Nova Southeastern University

Florida

\author{
Nova Southeastern University
}

NOVA SOUTHEASTERN

UNIVERSITY

NSUWorks

HCBE Faculty Articles

H. Wayne Huizenga College of Business and

Entrepreneurship

$1-21-2021$

\title{
Technology-Dependent Pedagogical Process Redesign: Leveraging Lean Methods
}

\author{
Kimberly Deranek \\ Nova Southeastern University, kderanek@nova.edu \\ Steven B. Kramer \\ Nova Southeastern University, sk863@nova.edu \\ Sharon C. Siegel \\ Nova Southeastern University, scsiegel@nova.edu
}

Follow this and additional works at: https://nsuworks.nova.edu/hcbe_facarticles

\section{NSUWorks Citation}

Deranek, Kimberly; Kramer, Steven B.; and Siegel, Sharon C., "Technology-Dependent Pedagogical Process Redesign: Leveraging Lean Methods" (2021). HCBE Faculty Articles. 1161.

https://nsuworks.nova.edu/hcbe_facarticles/1161

This Article is brought to you for free and open access by the $\mathrm{H}$. Wayne Huizenga College of Business and Entrepreneurship at NSUWorks. It has been accepted for inclusion in HCBE Faculty Articles by an authorized administrator of NSUWorks. For more information, please contact nsuworks@nova.edu. 
Technology-Dependent Pedagogical Process Redesign:

\section{Leveraging Lean Methods}

\begin{tabular}{|r|l|}
\hline Journal: & International Journal of Quality \& Reliability Management \\
\hline Manuscript ID & IJQRM-04-2020-0107 \\
\hline Manuscript Type: & Quality Paper \\
\hline Keywords: & Lean, Technology, Healthcare, Dentistry, Pedagogy, Quality \\
\hline Abstract: & \\
\hline \multicolumn{2}{|c}{} \\
\hline
\end{tabular}

\section{SCHOLARONE ${ }^{m}$}

Manuscripts 


\section{Technology-Dependent Pedagogical Process Redesign: Leveraging Lean Methods}

\section{Structured Abstract:}

Purpose - This research compared the efficacy of process outcomes leveraging lean methods versus traditional pedagogy applied to dental education dependent on emerging technology. The pedagogical objective was to improve system efficiency without compromising traditional outcomes of effectiveness (quality).

Design/methodology/approach - The research team tested the efficacy of a lean A3 framework to identify, remove waste, and redesign a technology-dependent simulation laboratory course (CAD/CAM/IR Restorative Dentistry). Students were also sensitized to time-in-chair to introduce a stronger patient focus. Baseline data collected from a control group were statistically compared to the research group's data after the course redesign. In addition, course time allocations were measured and then compared.

Findings - The results showed the interventions significantly reduced procedure cycle times without compromising quality. Additionally, the course was more efficiently conducted as measured by course time allocations.

Practical implications - This research demonstrated that the use of the A3 framework enhanced learning through process documentation, reengineering, and systems optimization resolving issues of inefficiency associated with the CAD/CAM/IR pedagogy. This work is significant because it demonstrates the practice of using lean interventions to redesign and improve a technology-based healthcare course to maximize benefits.

Originality/value - This research is the first to examine how to leverage lean methods in a healthcare simulation laboratory, dependent on innovative technology, to educate and train future practitioners. This research applied statistical rigor in a controlled experiment to maximize its applicability and generalizability.

Keywords: Lean, CAD/CAM, Technology, Healthcare, Dentistry, A3, Pedagogy, Quality, System 


\section{Introduction}

Technology is an enabler of process reengineering and it enhances customer value when implemented with consideration to both local and system-level improvements (Attaran, 2003; Hammer and Champy, 2005). It is important to assess underlying business processes from the customers' perspective when considering and implementing new technology. Businesses environments have long used lean methods to improve efficiency and enhance quality (Deming, 2000).

A key component of lean is the elimination or minimization of waste, or non-value-added process or process features within the operation. Common principles of the lean philosophy used to attain maximum value and reduce waste include: identifying the value to be produced from the customer's perspective; identifying the value stream (process); creating a smooth flow throughout the operation, eliminating delays; using the concept of pull by responding to the customers' demands by having the right resources ready for the needs at hand and finally; striving for perfection (kaizen) creating a culture of continuous improvement (Gupta and Jain, 2013). Use of a lean A3 framework is common practice to help identify, frame, and act on problems (Shook, 2008). The typical continuous improvement steps of the A3 process, according to Shook (2008), align with other quality improvement models such as the Deming (2000) PDCA (Plan-Do-Check-Act) cycle and Six Sigma’s DMAIC (Define, Measure, Analyze, Improve, Control) process.

Educators in the $21^{\text {st }}$ century are facing the responsibility of training with a focus on redesigning and optimizing processes resulting from the continuous evolution of technology (Graham, Culatta, Pratt, and West, 2004; Kim, Lecha, Agarwal, Bartlett, and Daniel, 2004). Educators have an opportunity to influence future professionals by using lean methods to 
redesign processes when embedding new technologies in their training. Technology alone is not a panacea: system integration considerations are necessary to ensure system optimization and maximization of all elements of customer value. Introducing future professionals to the importance of systematic process redesign during training enables students to understand the importance of process and technology alignment.

Recently healthcare has started incorporating lean into its practices (Antony, Sreedharan, Chakraborty, and Gunasekaran, 2019; Wataha, Mouradian, Slayton, Sorensen, and Berg, 2016; D'Andreamatteo, Ianni, Lega, and Sargiacomo, 2015). A recent review of the healthcare literature found only $45-51 \%$ of the studies used lean techniques to enhance operational performance (Radnor, 2010; Radnor, Holweg, and Waring, 2012; D'Andreamatteo et al., 2015; de Souza, 2009; Filser, da Silva, and de Olveiraz, 2017).

For example, emergency rooms apply lean management principles to minimize wait times and optimize admittance flow through the various departments of hospitals. This approach has been shown to improve the process efficiency of healthcare processes and procedures (Honeycutt and Keller, 2019; Hintzen, Knoer, Van Dyke, and Milavitz, 2009; Damle, Andrew, Kaur, Orquiola, Alavi, Steele, and Maykel, 2016; Crema and Verbano, 2016). The research team believes the incorporation of lean principles is an important consideration during process redesign in healthcare when incorporating emerging technology.

Simulation is a recognized phase of healthcare education: progressing from didactic to simulation to clinic. Simulation laboratories typically incorporate the essence of the actual clinical environment. Simulation laboratories in the healthcare field use technology to mimic a "real," but controlled environment. Healthcare faculty are now considering customer (patient) impact in the educational and clinical processes in simulation laboratories when incorporating 
technology (Filser et al., 2017; Reifeis, Kirkup, Willis, and Browning, 2014; Schwindling, Deisenhofer, Porsche, Rammelsberg, Kappel, and Stober, 2015; Delozier and Rhodes, 2017). However, consistent with lean management principles, it is also important to consider flow time and congestion in order to optimize the system. Lean principles are just now being considered in dental education and the delivery of oral health care due to dental schools' aspirations to assure good and efficient services (Wataha et al., 2016; Radnor, 2010; Robinson, Cunningham, Turner, Lindroth, Khan, and Yates, 2016). These studies used lean techniques without considering the key relationships between processes and technology.

Computer-assisted design/computer-assisted manufacturing/indirect dental restorative (CAD/CAM/IR) technology, introduced in 1987 in dental healthcare, has advanced significantly. $\mathrm{CAD} / \mathrm{CAM} / \mathrm{IR}$ has improved due to more accurate digital image capture and design modeling tools (Alghazzawi, 2016; Davidowitz and Kotick, 2011). This technology allows dentists to take digital impressions and create accurate models used for the fabrication of restorations within a single sitting that are accurate and esthetically pleasing (Baroudi and Ibraheem, 2015). This potentially removes the need for a temporary phase; the physical creation of a temporary crown that must then be replaced with the definitive restoration. The CAD/CAM/IR continually emerging technology has proven to be an effective replacement for many types of indirect dental restorative processes such as traditional impressions for crowns and onlays. A literature review assessing chairside $\mathrm{CAD} / \mathrm{CAM} / \mathrm{IR}$ restorations showed that it is effective, timesaving, and applied successfully in private practice (Baroudi and Ibraheem, 2015). This demonstrates emerging technology to support the optimization of oral health outcomes.

Dental schools are incorporating CAD/CAM/IR technology into their dental simulation laboratory training (Reifeis et al., 2014; Brownstein, Murad, and Hunt, 2015; Schweyen, Beuer, 
Bochskani, and Hey, 2017). As of 2015, 55\% of dental schools report teaching CAD/CAM/IR in the simulation laboratory and 58\% in clinical patient experience (Brownstein et al., 2015). Dental school faculty must ensure that the curriculum in the schools incorporates these modern technologies (Commission on Dental Accreditation, 2019).

While dental educators have introduced CAD/CAM/IR technology, they have not emphasized efficiency, a key feature of system optimization and the primary goal of CAD/CAM/IR. A study from the University of Kentucky's College of Dentistry (Robinson et al., 2016), used lean processes to improve clinical operations by reducing the "patient's average inthe-door-out-the-door-time" by one hour and improved patient satisfaction by $21 \%$. A topic of increasing interest in the delivery of healthcare in the U.S. is efficiency improvement without sacrificing quality (Massoud, Barry, Murphy, Albrecht, Sax and Parchman, 2016; Porter and Kramer, 2006; Miyazaki, Hotta, Kunii, Kuriyama and Tamaki, 2009). However, the dental literature research to date (2019) is scant. Robinson et al., (2016) positively affected patient satisfaction by identifying and eliminating waste between process steps. Lean process improvement tools in the dental educational environment may, therefore, reduce overall patient appointment times. Their study focused not on the clinical steps, themselves, but specifically on the times between clinic steps. They concluded that since there was not a significant increase in patient-generated incident reports (i.e. adverse outcomes and/or account adjustments due to patient complaints) that quality levels were not adversely impacted. This research was in a clinical setting but did not explicitly measure oral healthcare outcomes.

A systems optimization approach in the simulation phase (pre-clinical) of dental education ensures that any technologies applied would be considered with respect to all dimensions of quality. In dentistry, effectiveness includes oral health outcomes, and efficiency is 
measured by time-in-chair. The research team believes that incorporating technology, in concert with lean principles in the earlier phases (simulation) of dental pedagogy, would increase the likelihood of system optimization of dental education quality to include patient satisfaction (efficiency) and oral health outcomes (effectiveness). Schweyen et al., (2017) provided evidence that faculty and student application of CAD/CAM/IR techniques in the simulation lab led to increased productivity, which positively influenced student self-confidence in tooth preparation. Productivity, however, was only measured at the individual tooth level output and did not include the entire appointment time (time-in-chair). In addition, Schweyen et al., (2017) did not assess the impact on oral healthcare outcomes. Their paper looked at the application of technology, but not in the context of a systems approach in that it did not include both quality factors of effectiveness and efficiency.

More broadly, other researchers have considered other aspects of pedagogy that can positively affect systems when implementing technology independent of the dental education field. Two of these include learning curves and the use of a flipped classroom. Pusic, Boutis, Hatala, and Cook (2015) encourage the application of the learning curve theory, recognizing the use of repetitive work toward efficiencies, in health professions education. To enhance learning, a flipped classroom model has also been considered. This model enables autonomous learning by the student prior to coming to the classroom which frees up class time for additional interactive and collaborative activities (Park and Howell, 2015; DeLozier and Rhodes, 2017).

Maximizing class time for hands-on learning is essential. Specifically, dental students rely heavily on kinesthetic skill development to achieve efficiency and effectiveness that improves with practice. For dental education and more specifically simulation courses, the flipped classroom model would potentially allow students additional time to practice new 
technologies designed to enhance proficiency and future clinical success under the supervision of the instructor. This increased time with an instructor is important to allow students to gain immediate feedback to assess their knowledge and skill level, the key learning objectives of a simulation course. The purpose of this current research is to investigate if lean methods applied to dental healthcare training, dependent on emerging technology, can lead to improved system efficiency without compromising traditional outcomes of effectiveness. Our hypotheses are stated below:

H1: Process interventions will not reduce the time it takes to execute CAD/CAM/IR process steps.

$\mathrm{H} 2$ : Implementing process efficiencies will not change the oral health outcome level as measured by preparation grades.

\section{Methodology and Results}

An A3 framework inclusive of the following elements guided this research: Background, Current Conditions, Goals/Targets, Analysis, Proposed Countermeasures, Plan, and Follow-up (Shook, 2008, p 7).

\section{Step 1: Background}

The CAD/CAM/IR course (\#) at [Author(s)] University, College of Dental Medicine was delivered during the summer semester between the third and fourth years as a didactic as well as a simulation laboratory hands-on course. The original objective of the course was to teach proper protocol for all components of CAD/CAM tooth preparations and indirect restorations (use of technology to achieve oral health outcome effectiveness).

The course began in 2011 and included both didactic theory and hands-on simulation laboratory components. This course objective was to enable students to develop CAD/CAM/IR 
skills needed to treat their patients in the dental school clinic and later in their own dental practice. The simulation class was taught in the traditional way, incorporating lectures and demonstrations as well as hands-on practice time in the laboratory. This teaching methodology focused on quality only, without attention to time-in-chair. Students would graduate qualified to perform the procedure but without the same efficiency level required of a practicing dentist.

\section{Step 2: Current Condition}

Traditionally, the fabrication of crowns and onlays is a two-appointment visit. The first visit involves preparing the tooth, making a temporary (provisional) restoration, making the impression, and cementing the temporary restoration. In between appointments, the dentist sends the impression to the laboratory and approximately two weeks later the dentist receives the crown and makes an appointment for the patient. This second appointment involves fitting the restoration, adjusting as necessary and then cementing the restoration. CAD/CAM/IR has some of the same steps but does not require sending out the impression to a lab if the dentist can mill in-house. A typical single crown and bridge appointment does not exceed three hours. Table 1 lists approximate procedure times needed by an experienced dentist for completing traditional vs $\mathrm{CAD} / \mathrm{CAM}$ restorations. The time allotments were provided by a convenience sample of select practicing CAD/CAM dentists within the school's region.

Table 1. Procedure Time Comparison

Table 1 suggests that a CAD/CAM approach can typically be completed within one appointment. However, the use of CAD/CAM/IR performed by the students in the clinic was less efficient than traditional impression-making crown fabrication. This meant that within the clinical setting it took longer to complete, still requiring two or even three appointments. Because the students did not demonstrate a clear time-in-chair advantage using CAD/CAM/IR 
over traditional methods, it did not gain endorsement for incorporation by faculty into the clinic as a standard operating procedure.

Historically, students' demonstrated accuracy associated with the CAD/CAM/IR process. After the completion of the simulation course preceding their clinical experience, the dental students demonstrated effective skills with the CAD/CAM/IR process in terms of oral health outcomes. The restorations fit well and adhered to current dental standards. The oral health outcomes (effectiveness) carried over into the clinic and was not the issue with CAD/CAM/IR in the clinic, efficiency was.

Educators teaching prosthodontic procedures that included CAD/CAM/IR stayed with the conventional methods of completing indirect restorations, not understanding that the $\mathrm{CAD} / \mathrm{CAM} / \mathrm{IR}$ procedures have the potential to shorten procedure times. When introduced into the clinic, the same amount of time was allocated for both the traditional and CAD/CAM/IR procedures. The student dentists coming from the simulation $\mathrm{CAD} / \mathrm{CAM}$ course were not exposed to procedure times as listed in Table 1, but neither were the clinical educators (faculty and staff). Without an understanding of the time savings potential of CAD/CAM/IR, there was no clear reason to champion this technology. Faculty and staff did not want to use technology just for technology's sake.

\section{Step 3: Goals/Targets}

The purpose of this current research is to investigate if lean methods applied to dental pedagogy within a simulation course (CAD/CAM/IR), dependent on emerging technology, can lead to improved system efficiency without compromising quality effectiveness. We wanted to enable the dental students to provide quality restorations within a minimal sitting time, preferably within a single appointment (Table 1). 
The research team wanted to ensure students approached the same time standards as practicing dentists. Dentists employing CAD/CAM/IR leverage the reduced time-in-chair as a marketing tool to attract new patients. They can complete patients' prosthodontic treatment plans more efficiently (in a single sitting). The research team wanted to ensure students approached the same time standards as practicing dentists.

Step 4: Analysis

After obtaining IRB [\#] approval, the research team, with expertise in industrial engineering and process improvement methodologies, observed the operations of the CAD/CAM/IR course to gain understanding and identify inefficiencies [Author(s)]. The CAD/CAM/IR course consisted of senior dental students $(\mathrm{N} \sim 130)$ who were randomly assigned to one of four independent groups $(\mathrm{N} \sim 32)$. Groups 1 and 2 were taught in a traditional manner and were video recorded to aid in a post-course analysis. The research team discussed the operations of these two groups after hours to ensure all were familiar with the current operations of the course.

The CAD/CAM/IR course consisted of three full days ( $\sim 24$ class hours) of demonstrations and hands-on skill development and was conducted in the dental simulation laboratory. The students were required to show proficiency by scanning, designing, milling, characterizing, glazing and/or polishing and cementing one (1) onlay and one (1) crown. The oral healthcare outcomes of student CAD/CAM/IR tooth preparations were assessed using the same criteria used in previous course offerings. All tooth preparations were first self-evaluated by the students. Then the course directors, experts in the field of CAD/CAM/IR dentistry, evaluated them. 
The current state process map (Figure 1) illustrates the summary activities observed by the research team that comprised the $\mathrm{CAD} / \mathrm{CAM} / \mathrm{IR}$ procedures. Inefficiencies were identified by performing a waste analysis (Figure 2).

Figure 1. Instructor and Student Preliminary Process Maps

Figure 2. Course Waste Components

Inefficiencies were identified by performing a waste analysis (Figure 2). The research team identified the following waste components based on current state observations from Groups 1 and 2:

1) Defects: Lack of standard work guides governing the evaluation of the tooth preparation outcome led to student uncertainty. Students might have assessed their work as satisfactory while the instructor deemed the work unacceptable. This led to defects, requiring rework or necessitating the completion of a new preparation. Additionally, the students did the scanning on a benchtop, which did not replicate a clinical setting (in the patient's mouth). This could lead to improper scans or even patient injury/discomfort.

2) Waiting: This was a dominant observed form of waste. Some students arrived late to class causing delay to the start of productive class time. Additionally, students had to wait due to a limited number of $\mathrm{CAD} / \mathrm{CAM} / \mathrm{IR}$ scanning machines. Students were also idle during the milling and glazing processes due to a limited number of milling machines and glazing ovens. The milling operation was hands-free once the program was initiated, having a 9-22 minute run time (based on the type of mill that was used). Workstation congestion added to the milling time due to the limited number of machines. The students also had to compete for access to one of the two glazing ovens that had a 15 -minute run time and were also run as a batch process. This could cause students to wait in a queue for up to an additional 10 minutes until a complete batch was 
accumulated. Finally, students had to wait for the instructors to assess their work due to the limited number of instructors.

3) Overproduction: Not all teeth after being prepared to receive a crown using CAD/CAM/IR were subsequently scanned. This created a surplus inventory of prepared teeth, resulting in a lost learning opportunity. All students prepared eight teeth, but only scanned and designed two.

4) Overprocessing: Some students needlessly went past the needs of the preparation. They may have spent time precisely mimicking the anatomical form of the original tooth, but the crown would not require this level of detail to seat well. If this were to happen in a clinical setting, the patient could experience discomfort by having their mouth open for an excessive period.

5) Incorrect use of people: This class was held within the simulation laboratory, specifically designed to develop students' hands-on skills. Students observed instructor-led lectures instead of using that class time to improve hands-on skills. In addition, the faculty did not sensitize the students on the importance of time-in-chair, so the students did not feel compelled to complete their work in an efficient manner. In a clinic setting, this behavior would incorrectly affect the patient in excessive time-in-chair.

6) Motion: Lastly, there was also motion and transportation waste due to the need to move students and/or materials within the simulation laboratory classroom. This was in addition to the waste associated with waiting cited in \#2 above. This occurred when students had to walk across the room to interact with a professor to receive feedback associated with their work. It also occurred due to the limited number of machines (discussed above) causing students to relocate to available machines.

Step 5: Propose countermeasures 
A balanced experimental design was created using students from two different course sections (3 and 4) to gather comparative research data. The research team used the same oral healthcare outcomes of $\mathrm{CAD} / \mathrm{CAM} / \mathrm{IR}$ tooth preparations and cycle times to measure process efficiency and effectiveness. Students in the Control group (Group 3, N=32) were taught in the traditional manner to establish the baseline performance levels. Group 4 was the "Research" group (N=32) incorporated interventions to address the root causes of the waste (Figure 2).

1) Defects: The lack of standard work guides was addressed by the introduction of objective preparation standards, with the intent of providing students with a mechanism to self-assess their preparation quality. The introduction of the work guides was intended to have students no longer be dependent on a limited number of instructors for feedback on their progress. In addition, all scans were to be completed in a typodont within their mannequin head to mimic more of a clinical (complex) environment.

2) Waiting: The classroom was flipped and the recorded lectures and demonstrations from Groups 1 and 2 were made available to students before the course. Students were directed to be prepared to practice and master $\mathrm{CAD} / \mathrm{CAM} / \mathrm{IR}$ steps introduced in the videos. Quizzes were administered at the beginning of the class covering material from the required out-of-class video lectures (to support the flipped classroom). The quizzes were designed to accomplish two things: ensure prompt student arrival and their preparedness for the class activities. Since we introduced the new requirement for the Research group to scan and design all preparations, classroom tasks were able to be performed more asynchronously by students. This was intended to remove the lock-step classroom environment which had required all resources to be in demand at the same time. The introduction of the self-assessment preparation standards was designed to decrease congestion at the instructor. 
3) Overproduction: The Research group was instructed to use the balance of their preparations to practice scanning, thus consuming the balance of their teeth (a total of eight instead of two). They were also instructed to complete these additional scans in the corrected environment, in a typodont within a mannequin head.

4) Overprocessing: The introduction of objective preparation standards provided students with a mechanism to attempt self-assessment of the preparation criteria within clinically acceptable parameters. The preparation standard included a reference to different calibration mechanisms that students could leverage to self-assess. These mechanisms enabled precise tactical and/or visual feedback and included: flexible clearance tabs and ball burnishers for clearance, periodontal probes for finish line widths, and explorers to check (feel) for unacceptable J-hooks at the finish lines.

5) Incorrect use of people: The flipped classroom model allowed the time spent in the simulation laboratory to be more productive with hands-on learning. Students were directed to watch prerecorded videos and be prepared prior to entering the laboratory. They were expected to arrive ready to practice and develop their $\mathrm{CAD} / \mathrm{CAM} / \mathrm{IR}$ skills with faculty oversight.

The students were sensitized to the importance of patient time-in-chair at the beginning of the course. For the Research group, Table 1 was displayed on overheads throughout the laboratory, and the course director emphasized the importance of meeting the timing goals associated with all the sub-processes. The students in both groups were instructed to document their sub-process times associated with their $\mathrm{CAD} / \mathrm{CAM} / \mathrm{IR}$ procedures on a standard grading form. 
6) Motion: The distributed preparation standards allowed students to self-assess and reduce movement to instructors for feedback. Students still had to move to and from the equipment because it was limited and distributed throughout the simulation laboratory.

Step 6: Plan/Results

1) Defects: All scans were completed in a typodont within their mannequin head to mimic more of a clinical (complex) environment. This corrected the defect of the work previously not being done in the appropriate clinical setting.

The introduction of the objective preparation self-assessment standards reduced the time associated with student tooth preparations because they now had a mechanism to self-assess. The detailed statistics of the crown and onlay completion times as a function of group (Control vs Research) are included in Table 2 below.

Table 2. Crown and Onlay Preparation Statistical Comparisons

The data above indicates that none of the completion time distributions were normal in shape as indicated by Anderson-Darling (AD) p-values of less than 0.05. That required comparisons of medians using a nonparametric method. Mood's Median was used in all cases since the distributions included outliers. Then group variability was compared using Levene's test to compare samples with non-normal data for equal variances to assess any impact on completion time variability. The magnitude of the change in variability was measured using a Chi-Square comparison of the Research group's standard deviation to the Control for crown and onlay.

The Research group's preparation times overall (crowns and onlays) represent a reduction of at least 5 minutes in median process completion time as compared to the Control 
group (confidence $>95 \%$ ). In addition, there has been a reduction of more than 5 minutes (confidence $>95 \%$ ) in the standard deviation of these completion times.

The introduction of standard work guides did not affect the quality of the tooth preparations submitted by students between the Control and Research group (Table 3). There was no statistically significant difference in the quality of preparations between the Control and Research groups $(\mathrm{p}>0.05)$ for either crown or onlay preps based on the medians of instructor grades (Table 3). A change in grade variability as measured by standard deviations cannot be claimed either.

Table 3. Preparation Grades Statistical Comparisons

2) Waiting: Prior to the introduction of the morning quizzes in the Control group, the course start time was delayed approximately 20 minutes. By design, the introduction of the flipped classroom model and daily quiz decreased course delay by approximately 10 minutes per day resulting in a 30 minutes total savings over 3-days. Also, the flipped model and introduction of the self-assessment preparation standard enabled more time for students to perform hands-on skill development. Figure 3 shows the breakdown of the course into specific processes: lecture/demonstration/ administration, assessment (to the left of the dashed line) and hands-on (to the right of the dashed line).

Figure 3. Summary Comparison of Course Time Allotments

As a result, though students performed additional scans and designs of all preparations, they were able to do so according to their unique tempo. The students were able to ask for feedback when resources were available because they had other productive tasks they could be working on. This minimized wait time associated with competition for resources, including faculty feedback, machinery, and equipment, resulting in a savings of 24 minutes. There 
remained limited resources throughout the simulation laboratory, so several sub-process times were not affected by the flexibility of student scheduling of their demands. The net effect was a $14 \%$ reduction in congestion-related wait times for a total reduction of 54 minutes.

3) Overproduction: The total class time spent on scanning by the Research group almost tripled (Figure 3). With the use of a flipped classroom model, the students in the Research group were able to scan on average over three times the number of teeth than those students in the Control group (in the mannequin heads). Similarly, the hands-on class time spent on design in the Research group tripled. The number of designs completed per student increased from an average of 1.7 to 4.9 .

The data below (Table 4) indicates that none of the completion time distributions were normal in shape as indicated by Anderson-Darling (AD) p-values of less than 0.05 . That required comparisons of medians using a nonparametric method. Mood's Median was used in all cases since the distributions included outliers. Then group variability was compared using Levene's test to compare samples with non-normal data for equal variances to assess any impact on completion time variability. The magnitude of the change in variability was measured using a Chi-Square comparison of the Research group's standard deviation to the Control for the crown and onlay.

Table 4. Crown and Onlay Scan and Design Statistical Comparisons

The Research group's (median) scan times were not significantly lower than the Control group, however, they executed their scans within the mannequin head, a more constrained environment. The design times, however, were significantly lower than the Control group as measured by the medians. The variability of scan and design times did not change as measured by the standard deviations. 
4) Overprocessing: The introduction of the objective preparation standards ensured students had criteria to assess whether clinically acceptable parameters were met, minimizing overprocessing without over-reliance on instructors. Students were guided as to the magnitude and detail of their preparations with the new specific visual aid guides and tools. Additionally, because students were sensitized to the 120-minute appointment time, they were motivated to prepare the tooth to achieve the 20-minute preparation target (Table 1). Table 2 specifies the realized improvements (reductions) in preparation times as well as the reduction in variability in preparation times. The median crown preparation of 10 minutes in our sample indicated at least a 4-minute reduction ( $95 \% \mathrm{CI})$ for students in this population. In addition, the standard deviation for crown preparation can be expected to be reduced at least 5.5 minutes (population). The 8-minute median sample reduction for onlay preparations indicated a significant $(95 \% \mathrm{CI})$ reduction, too. The variability reduction suggests a 7.5 minute expected reduction in standard deviation of the population.

5) Misuse of people: Student cycle times decreased through student iterations of the $\mathrm{CAD} / \mathrm{CAM} / \mathrm{IR}$ processes. Even though students in the Research group scanned in the mannequin head, their median scan times were not significantly different $(\mathrm{p}>0.05)$ as listed in Table 4. The average Research group student completed 3.3 times the average Control group scans (170 total vs 51$)$. The median design time was reduced 8 minutes suggesting a significant population time reduction $(\mathrm{p}<0.05)$ based on the Research group designing 3.1 times the teeth of the Control group (157 vs 51). The standard deviation had no statistically discernible change ( $>0.05)$. Because students did more of the same work, they ultimately became more proficient, leading to improvements in scanning and design efficiencies. 
The course time distribution associated with the modified CAD/CAM/IR sub-processes was measured during the course delivery of the Research group as illustrated in Figure 3. The instructor's in-class demonstration-lecture time decreased by 80 minutes from 250 to 170 . The original wait was reduced from 626 to 331 minutes leaving 307 minutes of unallocated (potential) time for in-class productivity. The course time for preparations (358 vs 248) was lower in the Research group. The course time for scanning increased from 37 to 106 to accommodate the additional scans (done in the mannequin). Similarly, students used their additional prepared and scanned teeth during the design sub-process which required 163 minutes of course time instead of 54 in the Control group. The finishing sub-processes mill, fit, characterize and cement and their associated course times did not change.

6) Motion: As mentioned above, the introduction of the objective preparation standards ensured students had criteria to achieve clinically acceptable parameters. In addition to minimizing overprocessing, it also enabled students to self-assess without over-reliance on instructors, therefore, minimizing waste in movement (Figure 3).

Other Results

The post-mill fit, polish, characterize and cement completion times as a function of group (Control vs Research) were not the focus of this study, but were measured to test for any unintended impacts. The between group's mill, fit, post-mill fit, polish, and adjust activity (median) times were not significantly different.

Step 7: Follow-up

The interventions were planned with an eye towards implementation and standard work. Students are now informed prior to the beginning of the term of the flipped nature of the course and the two-hour time goal to fit within a single typical appointment time. The implications of 
their study habits are also pointed out. This detail is sent out a week prior to the term start to enable students to start viewing the videos and preparing for the hands-on work in the simulation laboratory starting the first day of class. The students are also advised that a morning quiz will be administered at the beginning of each period to encourage them to be adequately prepared for each session, as well as being to class on time. The flipped model continues to be used and maximizes the use of hands-on learning within the simulation laboratory. The two-hour appointment time goal with elemental time breakouts is the first detail that is clearly illustrated and posted prominently in the simulation laboratory to sensitize students to the criticality of process efficiency in addition to process effectiveness. Additionally, the use of visual aids and standard work guides, inclusive of calibration mechanisms, have been integrated by the faculty into the classroom to guide student work and enable their independent evaluation of quality as they proceed in skill development.

\section{Discussion}

This research disproved the H1 hypothesis, confirming the ability to improve course procedure time efficiencies. At the same time, there was not sufficient evidence that healthcare quality outcomes, as measured by preparation grades, had degraded (H2). This optimized the use of technology for the good of the patient. Use of the A3 process enhanced learning through process documentation, reengineering, and systems optimization resolving issues of inefficiency associated with the CAD/CAM/IR pedagogy. The use of the A3 framework also resulted in more time for practical hands-on training and the reduction of waste (Figure 3 ) in a CAD/CAM/IR course that uses innovative technology.

Generalizable Framework 
This new awareness of the ability to reduce time-in-chair through the efficient use of technology can be applied in other preclinical dental courses to teach theories and develop skills without compromising clinical quality outcomes. Similarly, the results can impact the succeeding step, the clinic, in adopting the new understandings of technology-based processes toward time-inchair reduction. Through the incorporation of lean processes in the pedagogy of dental courses, the research team anticipate students will be more prepared for their time-constrained Board exams since they are more efficient in tooth preparation.

The framework adopted for this study is not specific to dental education. The research team believes it also applies to healthcare in general and to other fields leveraging technology. In particular, it is relevant in hands-on technology-based laboratory simulation environments.

Within healthcare pedagogy, faculty educate and assist students achieve the necessary skills needed to both effectively and efficiently utilize innovative technology in private practice. Upon completion of formal university-based education, healthcare professionals need to be aware of how to successfully set up a private practice, including the ability to evaluate and purchase equipment, implement innovative technology, define procedures, and train administrative staff. Healthcare professionals use some of the most advanced technology in the world. The objective is to ensure that technology is effectively and efficiently leveraged toward patient satisfaction and clinical outcomes. Without defining, evaluating, and optimizing processes for the good of the system, the desired results may not be achieved.

Outside of healthcare, educators have an opportunity to train future practitioners leveraging process reengineering and continuous improvement methodologies. This is especially true in fields using technology-based hands-on training. Educators can maximize the 
efficiencies/effectiveness in engineering, biology, chemistry, education, meteorology, etc.

Educators can transfer out formative "lecture" materials to remove waste and maximize handson, value-added course time in an improved state. They can couple technology-based knowledge, exploration, and skill enhancement with built-in feedback mechanisms, optimizing the learning system.

Process redesign is an essential precursor to implementing technology of any kind. Technology alone may not improve the outcome or allow users to achieve desired results if inefficient or sub-standard processes exist. Practitioners in different disciplines need to be trained to assess processes as a first step in any initiative involving the implementation of technology. Process and technology alignment is key. In the event that this step is overlooked, practitioners may incur unnecessary costs associated with customization or, as previously mentioned, may be disappointed with the final result. A solution would be the adoption of a continuous improvement methodology. The research team found the application of the A3 process to be an easy and intuitive approach to re-engineer processes associated with the use of technology, in a hands-on setting. This research suggests its broad applicability.

\section{Future Research}

The next logical step in this research is assessing the impact of the use of lean methods associated with CAD/CAM IR processes in the clinic, another environment utilizing technology. Here, the CAD/CAM IR process is intermixed with a number of other dental processes, which would allow for a more comprehensive view of system optimization. Processes could be enhanced, and technology applied to give students immediate quality feedback. This may enable students to continue their skill development outside of the (artificial) class time structure. 
Students with access to the feedback technology could work more autonomously, on their own time, to achieve cycle time goals while maintaining clinical quality standards.

\section{Limitations of the Study}

One limitation of this study was that student processing times were self-reported. To counter this, the research team was diligent in reminding students to capture their processing times throughout the study in real-time. Additionally, a reminder was displayed on monitors to encourage compliance.

Another limitation was that an inter- or intra-rater reliability analysis was not performed. The assessment variability was minimized by using only two faculty members. The faculty members discussed tooth preparation outcomes and came to a consensus on quality levels and grading criteria prior to assessing students' work. The same attributes were used to assess quality outcome measures across all groups.

\section{Conclusion}

Lean is a recognized process management approach used to enhance quality (value) while improving process flow. When instructors sensitize student clinicians that lean is a tool that provides this insight, students can gain an appreciation for lean management principles while learning to use new technology. This study used lean methods to improve the technology-driven CAD/CAM Restorative Dentistry course while maintaining its outcome quality. Re-engineering the entire $\mathrm{CAD} / \mathrm{CAM} / \mathrm{IR}$ pedagogy and reducing class time waste had a significant positive impact on students by increasing the time available for hands on skill development by $21 \%$. Specifically, after sensitizing students to the importance of the single-sitting appointment, the tooth preparation and design sub-process cycle times were significantly reduced while quality oral health outcomes were sustained at the previous high level. The scanning process was re- 
engineered to be performed in a more realistic, complex setting. The clinical implications are that when lean processes are incorporated into technology-dependent dental courses, students have an opportunity to maximize value-added time, thereby optimizing system (course) design outcomes. This class is now better focused on its mission of hands-on practice to foster skill development to support a private practice environment that demands quality with efficiency. 


\section{References}

Alghazzawi, T. F. (2016). “Advancements in CAD/CAM technology: Options for practical implementation." Journal of Prosthodontic Research, Vol. 60, pp. 72-84.

Antony, J., Sreedharan, R., Chakraborty, A., and Gunasekaran, A. (2019). “A systematic review of Lean in healthcare: a global prospective." International Journal of Quality \& Reliability Management, Vol. 36 No. 8, pp. 1370-1391.

Attaran, M. (2004). "Exploring the relationship between information technology and business process reengineering". Information and Management, Vol. 41, pp. 585-596.

Baroudi, K. and Ibraheem, S. N. (2015). “Assessment of chair-side computer-aided design and computer-aided manufacturing restorations: a review of the literature". Journal of International Oral Health, Vol. 7 No.4, pp. 96-104.

Brownstein, S. A., Murad, A. and Hunt, R. J. (2015). "Implementation of new technologies in US dental school curricula”. Journal of Dental Education, Vol. 79 No. 3, pp. 259-264.

Commission on Dental Accreditation (2019). Accreditation standards for advanced dental education programs prosthodontics. American Dental Association, Chicago, IL, available at https://www.ada.org/en/coda/current-accreditation-standards.

Crema, M., and Verbano, C. (2016). "Safety improvements from health lean management implementation". International Journal of Quality \& Reliability Management, Vol. 33 No. 8, pp. 1150-1178.

D’Andreamatteo, A., Ianni, L., Lega, F. and Sargiacomo, M. (2015). "Lean in healthcare: A comprehensive review". Health Policy, Vol. 119 No.9, pp. 1197-1209. 
Damle A., Andrew, N., Kaur, S., Orquiola, A., Alavi, K., Steele, S. R. and Maykel, J. (2016). "Elimination of waste: creation of a successful Lean colonoscopy program at an academic medical center". Surg Endoscopy, Vol. 30 No. 7, pp. 3071-3076.

Davidowitz, G. and Kotick, P. G. (2011). "The use of CAD/CAM in dentistry”. Dental Clinic North America, Vol. 55, pp. 559-570.

DeLozier, S. J. and Rhodes, M. G. (2017). "Flipped classrooms: A review of key ideas and recommendations for practice". Educational psychology review, Vol. 29 No. 1, pp. 141151.

Deming, W. E. (2000). Out of the crisis, MIT Press, Cambridge, MA.

De Souza, L. B. (2009). "Trends and approaches in lean healthcare”. Leadership Health Services, Vol. 22 No.2, pp. 121-139.

Filser, L. D., da Silva, F. and de Olveiraz, O. J. (2017). "State of research and future research tendencies in lean healthcare: A bibliometric analysis". Scientometrics, Vol. 112 No.2, pp. 799-816. DOI 10.1007/s11192-017-2409-8

Graham C., Culatta, R., Pratt, M. and West, R. (2013). "Redesigning the teacher education technology course to emphasize integration”. Computers in the Schools, Vol. 21 No. 1-2, pp. 127-148.

Gupta S., and Jain, S.K. (2013). “A literature review of lean manufacturing”. International Journal of Management Science and Engineering Management, Vol. 8 No. 4, pp. 241249.

Hammer, M. and Champy, J. (2005). Reengineering the corporation: Manifesto for business revolution, HarperCollins, New York, NY. 
Hintzen B. L., Knoer, S. J., Van Dyke, C. J. and Milavitz, B. S. (2009). "Effect of lean process improvement techniques on a university hospital inpatient pharmacy". Am J Health-Syst Pharm, Vol. 66, pp. 2042-2047.

Honeycutt L. C. and Keller, S.D. (2019). "Effectiveness of the lean process compared to other quality improvement initiatives on length of stay and wait times in healthcare organizations: a systematic review protocol”. J Nurs Care Qual, Vol. 34 No. 1, pp. 6165. doi: 10.1097/NCQ.0000000000000332.

Kim, S., Lecha, B. J., Agarwal, R., Bartlett, R. L. and Daniel, J. I. (2004). "Efficiency in the use of technology in economic education: Some preliminary results”. American Economic Review, Vol. 94 No. 2, pp. 253-258. DOI: 10.1257/0002828041301623

Massoud, M. R., Barry, D., Murphy, A., Albrecht, Y., Sax, S. and Parchman, M. (2016). "How do we learn about improving health care?: A call for a new epistemological paradigm”. International Journal for Quality in Health Care, Vol. 28 No.3, pp. 420-424.

Miyazaki, T., Hotta, Y., Kunii, J., Kuriyama, S. and Tamaki, Y. (2009). “A review of dental CAD/CAM: current status and future perspectives from 20 years of experience". Dental Mater Journal, Vol. 28, pp. 44-56.

Park, S. E. and Howell, T. H. (2015). "Implementation of a flipped classroom educational model in a predoctoral dental course". Journal of Dental Education, Vol. 79 No. 5, pp. $563-570$.

Porter, M. E. and Kramer, M. R. (2006). "Strategy and society: The link between competitive advantage and corporate social responsibility". Harvard Business Review, Vol. 12, pp. 114. 
Pusic, M. V., Boutis, K., Hatala, R. and Cook, D. A. (2015). "Learning curves in health professions education”. Academic Medicine, Vol. 90 No. 8, pp. 1034-1042.

Radnor, Z. J. (2010). Review of business process improvement methodologies in public services (pp.1-94). London: AIM Research.

Radnor, Z. J., Holweg, H. and Waring, J. (2012). “Lean in healthcare: The unfilled promise?”. Social Science and Medicine, Vol. 74 No. 3, pp. 364-371. ISSN 0277-9536.

Reifeis P. E., Kirkup, M. L., Willis, L. H. and Browning, W. D. (2014). “Introducing CAD/CAM into a predoctoral dental curriculum: A case study". Journal of Dental Education, Vol. 78 No. 10, pp. 1432-1441.

Robinson, F. G., Cunningham, L. L., Turner, S. P., Lindroth, J., Ray, D., Khan, T. and Yates, A. (2016). “Improving a dental school's clinic operations using lean process improvement". Journal of Dental Education, Vol. 80 No. 10, pp. 1170-1179.

Schweyen, R., Beuer, F., Bochskani, M. and Hey, J. (2018). "Implementing a new curriculum for computer-assisted restorations in prosthetic dentistry". Eur Journal of Dental Education, Vol. 22 No.2, pp. 237-247.

Schwindling F. S., Deisenhofer, U. K., Porsche, M., Rammelsberg, P., Kappel, S. and Stober, T. (2015). "Establishing CAD/CAM in preclinical dental education: Evaluation of a handson module". Journal of Dental Education, Vol. 79 No. 10, pp. 1215-1221.

[Author(s)]

Shook, J. (2008). Managing to learn: Using the A3 management process to solve problems, gain agreement, mentor, and lead, The Lean Enterprise Institute,Cambridge, MA. 
Wataha, J. C., Mouradian, W. E., Slayton, R. L., Sorensen, J. A. and Berg, J. A. (2016).

"Modern management principles come to the dental school". Journal of Dental

Education, Vol. 80 No. 4, pp. 393-402. 


\begin{tabular}{|c|c|c|c|}
\hline Process Step & $\begin{array}{l}\text { Patient in } \\
\text { chair? } \\
(Y / N)\end{array}$ & $\begin{array}{l}\text { Procedure time } \\
\text { using impression } \\
\text { method (minutes) }\end{array}$ & $\begin{array}{l}\text { Procedure time } \\
\text { using CAD/CAM } \\
\text { method (minutes) }\end{array}$ \\
\hline Seat the patient & $\mathrm{Y}$ & 5 & 5 \\
\hline Anesthetize the patient & $\mathrm{Y}$ & 10 & 10 \\
\hline $\begin{array}{l}\text { Modify (prepare) the tooth to receive a } \\
\text { crown or onlay }\end{array}$ & $\mathrm{Y}$ & 20 & 20 \\
\hline Fabricate a provisional restoration & $\mathrm{Y}$ & 15 & $\mathrm{~N} / \mathrm{A}$ \\
\hline $\begin{array}{l}\text { Manage tissue prior to impression } \\
\text { making }\end{array}$ & Y & 10 & $\mathrm{~N} / \mathrm{A}$ \\
\hline $\begin{array}{l}\text { Make an impression using a stock or } \\
\text { custom tray }\end{array}$ & $\mathrm{Y}$ & 7 & $\mathrm{~N} / \mathrm{A}$ \\
\hline Cement the provisional restoration & $\mathrm{Y}$ & 10 & $\mathrm{~N} / \mathrm{A}$ \\
\hline Dismiss the patient & $\mathrm{Y}$ & 5 & $\mathrm{~N} / \mathrm{A}$ \\
\hline $\begin{array}{l}\text { Scan the prepared tooth and surrounding } \\
\text { area }\end{array}$ & $\mathrm{Y}$ & $\mathrm{N} / \mathrm{A}$ & 4 \\
\hline Create tooth design on CAD terminal & $\mathrm{Y}$ & $\mathrm{N} / \mathrm{A}$ & 5 \\
\hline Locally mill crown & $\mathrm{Y}$ & $\mathrm{N} / \mathrm{A}$ & 15 \\
\hline Disinfect the impression & $\mathrm{N}$ & 7 & $\mathrm{~N} / \mathrm{A}$ \\
\hline $\begin{array}{l}\text { Box the materials for the laboratory to } \\
\text { fabricate the restoration (opposing cast, } \\
\text { impression, diagnostic wax-up, etc.) }\end{array}$ & $\mathrm{N}$ & 5 & $\mathrm{~N} / \mathrm{A}$ \\
\hline Mail the materials to the laboratory & $\mathrm{N}$ & 5 & $\mathrm{~N} / \mathrm{A}$ \\
\hline $\begin{array}{l}\text { Receive the crown from the lab; perform } \\
\text { Quality Assurance of the work (fit to } \\
\text { master die, color, structural integrity }\end{array}$ & $\mathrm{N}$ & 5 & $\mathrm{~N} / \mathrm{A}$ \\
\hline Appoint the patient & $\mathrm{N}$ & 3 & $\mathrm{~N} / \mathrm{A}$ \\
\hline Seat the patient & $\mathrm{Y}$ & 5 & $\mathrm{~N} / \mathrm{A}$ \\
\hline Buff restoration & $\mathrm{Y}$ & $\mathrm{N} / \mathrm{A}$ & 5 \\
\hline $\begin{array}{l}\text { Try the restoration in the mouth, adjust } \\
\text { contacts and occlusion (fit, fit and floss } \\
\text { check, check bite) }\end{array}$ & $\mathrm{Y}$ & 20 & 10 \\
\hline Characterize (colorize) & $\mathrm{Y}$ & 4 & 4 \\
\hline Glaze (set the colorization) & $\mathrm{Y}$ & 25 & 25 \\
\hline Pre-cement radiograph & $\mathrm{Y}$ & 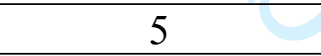 & 2 \\
\hline Cement the restoration & $\mathrm{Y}$ & 10 & 10 \\
\hline Post-cement radiograph & $\mathrm{Y}$ & 5 & 5 \\
\hline Dismiss patient & $\mathrm{Y}$ & 5 & 5 \\
\hline Write note & $\mathrm{N}$ & 5 & 5 \\
\hline Sum of patient in chair time & & 161 & 128 \\
\hline Sum of time with patient not in chair & & 30 & 5 \\
\hline
\end{tabular}

Table 1. Procedure Time Comparison 


\begin{tabular}{|c|c|c|c|}
\hline & Control & Research & Difference \\
\hline Students in Group (n) & 30 & 32 & \\
\hline Crown Preparations & 113 & 126 & \\
\hline Time distribution AD Normality Test: A-squared & 2.438 & 3.200 & \\
\hline AD Normality Test: P-Values & 0.000 & 0.000 & \\
\hline Outliers? & yes & yes & \\
\hline Median (sample) & 40 & 30 & -10 \\
\hline Mood's Median Chi-Squared $(\mathrm{df}=1)$ & \multicolumn{2}{|c|}{14.387} & \\
\hline P-Value (2-sided) & \multicolumn{2}{|c|}{0.000} & \\
\hline Median 2-sided, 95\% CI & $39-45$ & $27-35$ & $>-4$ \\
\hline Standard Deviation & 21.723 & 14.365 & \\
\hline $\begin{array}{l}\text { Levene's Test for Equal Variance: Statistic } \\
(\mathrm{df}=1,237)\end{array}$ & \multicolumn{2}{|c|}{14.015} & \\
\hline Levene's Test for Equal Variance: P-Value & \multicolumn{2}{|c|}{0.0002} & \\
\hline Chi-Square test for change in standard deviation & 21.723 & 14.365 & $>-5.5$ \\
\hline Chi-Square test statistic $(\mathrm{df}=125)$ & \multirow{2}{*}{\multicolumn{2}{|c|}{$\begin{array}{l}98.004 \\
0.036\end{array}$}} & \\
\hline P-Value (1-sided) & & & \\
\hline Onlay Preparations & 110 & 122 & \\
\hline Time distribution AD Normality Test: A-squared & 3.390 & 3.179 & \\
\hline AD Normality Test: P-Values & 0.000 & 0.000 & \\
\hline Outliers? & yes & yes & \\
\hline Median (sample) & 35 & 27 & -8 \\
\hline Mood's Median Chi-Squared $(\mathrm{df}=1)$ & \multicolumn{2}{|c|}{20.568} & \\
\hline P-Value (2-sided) & \multicolumn{2}{|c|}{0.000} & \\
\hline Median 2-sided, 95\% CI & $30-45$ & $25-30$ & $>-0$ \\
\hline Standard Deviation & 22.868 & 13.607 & \\
\hline $\begin{array}{l}\text { Levene's Test for Equal Variance: Statistic } \\
(\mathrm{df}=1,230)\end{array}$ & \multicolumn{2}{|c|}{12.300} & \\
\hline Levene's Test for Equal Variance: P-Value & \multicolumn{2}{|c|}{0.001} & \\
\hline Chi-Square test for change in standard deviation & 22.868 & 13.607 & $>-7.5$ \\
\hline Chi-Square test statistic $(\mathrm{df}=125)$ & \multirow{2}{*}{\multicolumn{2}{|c|}{$\begin{array}{c}94.856 \\
0.038\end{array}$}} & \\
\hline P-Value (1-sided) & & & \\
\hline
\end{tabular}

Table 2. Crown and Onlay Preparation Statistical Comparisons 


\begin{tabular}{|c|c|c|c|}
\hline & Control & Research & Difference \\
\hline Students in Group (n) & 30 & 32 & \\
\hline Crown Preparation Grades & 113 & 126 & \\
\hline $\begin{array}{l}\text { Grade distribution AD Normality Test: A- } \\
\text { squared }\end{array}$ & 1.4099 & 1.7056 & \\
\hline AD Normality Test: P-Values & 0.0011 & 0.0002 & \\
\hline Outliers? & yes & yes & \\
\hline Median (sample) & $94 \%$ & $94 \%$ & $0 \%$ \\
\hline Mood's Median Chi-Squared $(\mathrm{df}=1)$ & \multicolumn{2}{|c|}{3.5170} & \\
\hline P-Value (2-sided) & \multicolumn{2}{|c|}{0.0607} & \\
\hline Median 2-sided, 95\% CI & $93.4 \%-95 \%$ & $92.6 \%-94 \%$ & $0 \%$ \\
\hline Standard Deviation & 0.0379 & 0.0491 & \\
\hline $\begin{array}{l}\text { Levene's Test for Equal Variance: Statistic } \\
(\mathrm{df}=1,237)\end{array}$ & \multicolumn{2}{|c|}{3.7535} & \\
\hline Levene's Test for Equal Variance: P-Value & \multicolumn{2}{|c|}{0.0539} & $0 \%$ \\
\hline Onlay Preparation Grades & 119 & 125 & \\
\hline AD Normality Test: A-squared & 3.9716 & 1.7578 & \\
\hline AD Normality Test: P-Values & 0.0000 & 0.0002 & \\
\hline Outliers? & yes & no & \\
\hline Median (sample) & $94 \%$ & $94 \%$ & $0 \%$ \\
\hline Mood's Median Chi-Squared $(\mathrm{df}=1)$ & \multicolumn{2}{|c|}{1.8690} & \\
\hline P-Value (2-sided) & \multicolumn{2}{|c|}{0.1716} & \\
\hline Median 2-sided, 95\% CI & $94 \%-95 \%$ & $93 \%-94 \%$ & $0 \%$ \\
\hline Standard Deviation & 5.0656 & 4.9141 & \\
\hline $\begin{array}{l}\text { Levene's Test for Equal Variance: Statistic } \\
(\mathrm{df}=1,242)\end{array}$ & \multicolumn{2}{|c|}{0.2494} & \\
\hline Levene's Test for Equal Variance: P-Value & \multicolumn{2}{|c|}{0.6180} & $0 \%$ \\
\hline
\end{tabular}

Table 3. Preparation Grades Statistical Comparisons 
Time distribution AD Normality Test: A-squared

AD Normality Test: P-Values

Outliers?

Median (sample)

Mood's Median Chi-Squared $(\mathrm{df}=1)$

P-Value (2-sided)

Median 2-sided, 95\% CI

Standard Deviation

Levene's Test for Equal Variance: Statistic $(\mathrm{df}=1,219)$

Levene's Test for Equal Variance: P-Value

Designs

AD Normality Test: A-squared

AD Normality Test: P-Values

Outliers?

Median (sample)

Mood's Median Chi-Squared $(\mathrm{df}=1)$

P-Value (2-sided)

Median 2-sided, 95\% CI

Standard Deviation

Levene's Test for Equal Variance: Statistic $(\mathrm{df}=1,206)$

Levene's Test for Equal Variance: P-Value

Table 4. Crown and Onlay Scan and Design Statistical Comparisons

51

Research

1.701

170

0.000

6.791

no

0.000

10

yes

$7-15$

22.868

15.622

\section{Difference}

10

0

\subsection{1}

0.543

10-10

13.607

0.128

51

\subsection{1}

157

2.455

4.439

0.000

0.000

yes

yes

25

8.511

0.004

$\begin{array}{ccc}20-30 & 15-20 & >-0 \\ 15.622 & 12.554 & \\ & 0.273\end{array}$

0.602
$-8$

0

(

$-8$ $-0$ 


\begin{tabular}{|c|c|c|c|c|c|c|}
\hline $\begin{array}{c}\text { Crown/Onlay Prep } \\
\text { Demo }\end{array}$ & $\begin{array}{c}\text { Crown/Onlay } \\
\text { Prep } \\
\text { Assessment }\end{array}$ & $\begin{array}{l}\text { Crown/Onlay } \\
\text { Scan Demo }\end{array}$ & $\begin{array}{l}\text { Crown/Onlay } \\
\text { Design Demo }\end{array}$ & $\begin{array}{l}\text { Crown/Onlay } \\
\text { Milling Demo }\end{array}$ & $\begin{array}{c}\text { Crown/Onlay } \\
\text { Stain \& Glaze } \\
\text { Demo }\end{array}$ & $\begin{array}{c}\text { Crown/Onlay } \\
\text { Cement } \\
\text { Demo }\end{array}$ \\
\hline
\end{tabular}

Instructor Activities - Preliminary Process Map

\begin{tabular}{l|ccccc}
$\begin{array}{c}\text { Prep \& Self- } \\
\text { Assessment } \\
\text { Crown/Onlay }\end{array}$ & $\begin{array}{c}\text { Scan } \\
\text { Crown/Onlay }\end{array}$ & $\begin{array}{c}\text { Design } \\
\text { Crown/Onlay }\end{array}$ & $\begin{array}{c}\text { Mill } \\
\text { Crown/Onlay }\end{array}$ & $\begin{array}{c}\text { Fit } \\
\text { Adjustment } \\
\text { Crown/Onlay }\end{array}$ & $\begin{array}{c}\text { Stain \& Glaze } \\
\text { Crown/Onlay }\end{array}$
\end{tabular} $\begin{gathered}\text { Cement } \\
\text { Crown/Onlay }\end{gathered}$

Student Activities - Preliminary Process Map

Figure 1. Instructor and Student Preliminary Process Maps 
Figure 2. Course Waste Components 


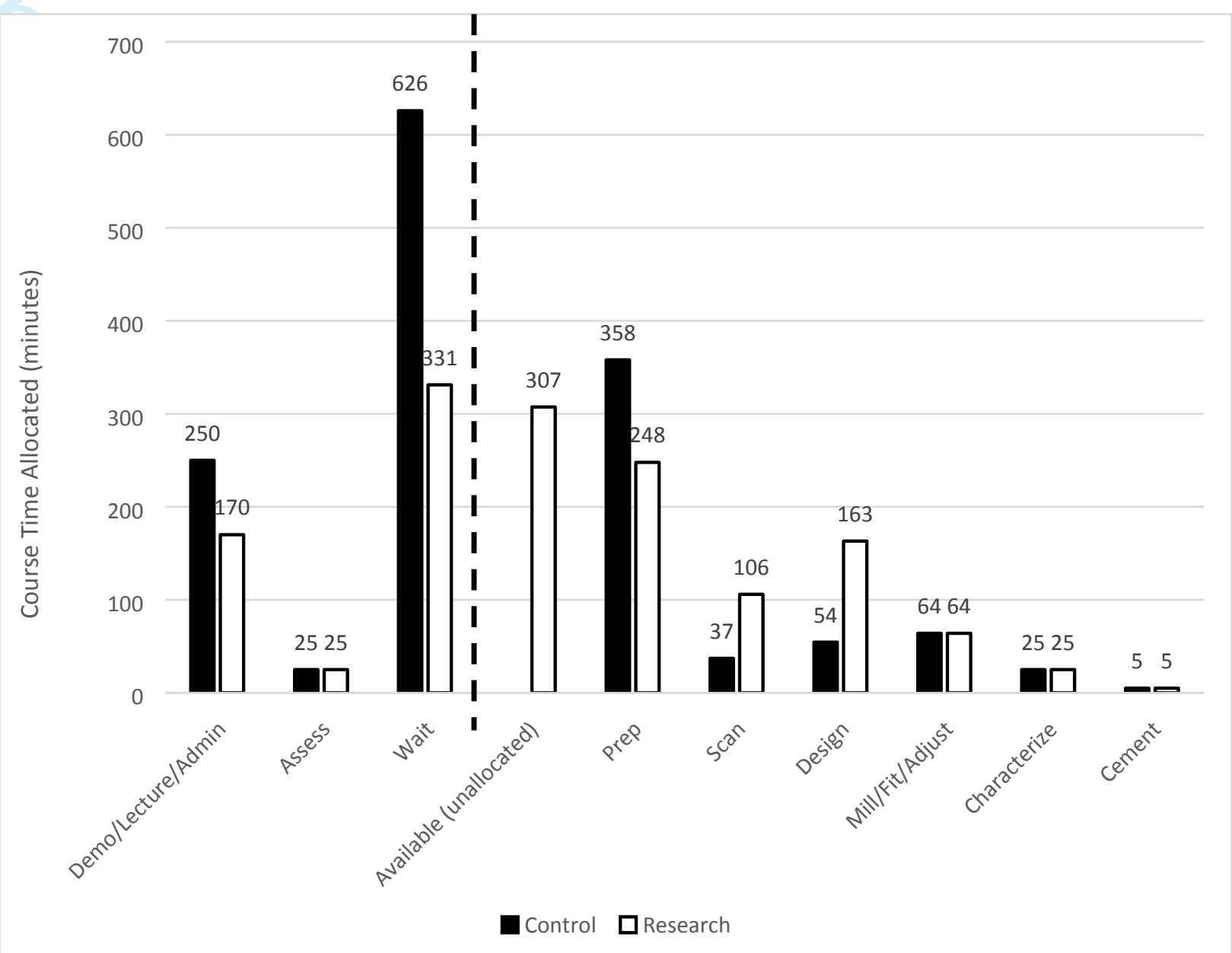

Figure 3. Summary Comparison of Course Time Allotments 


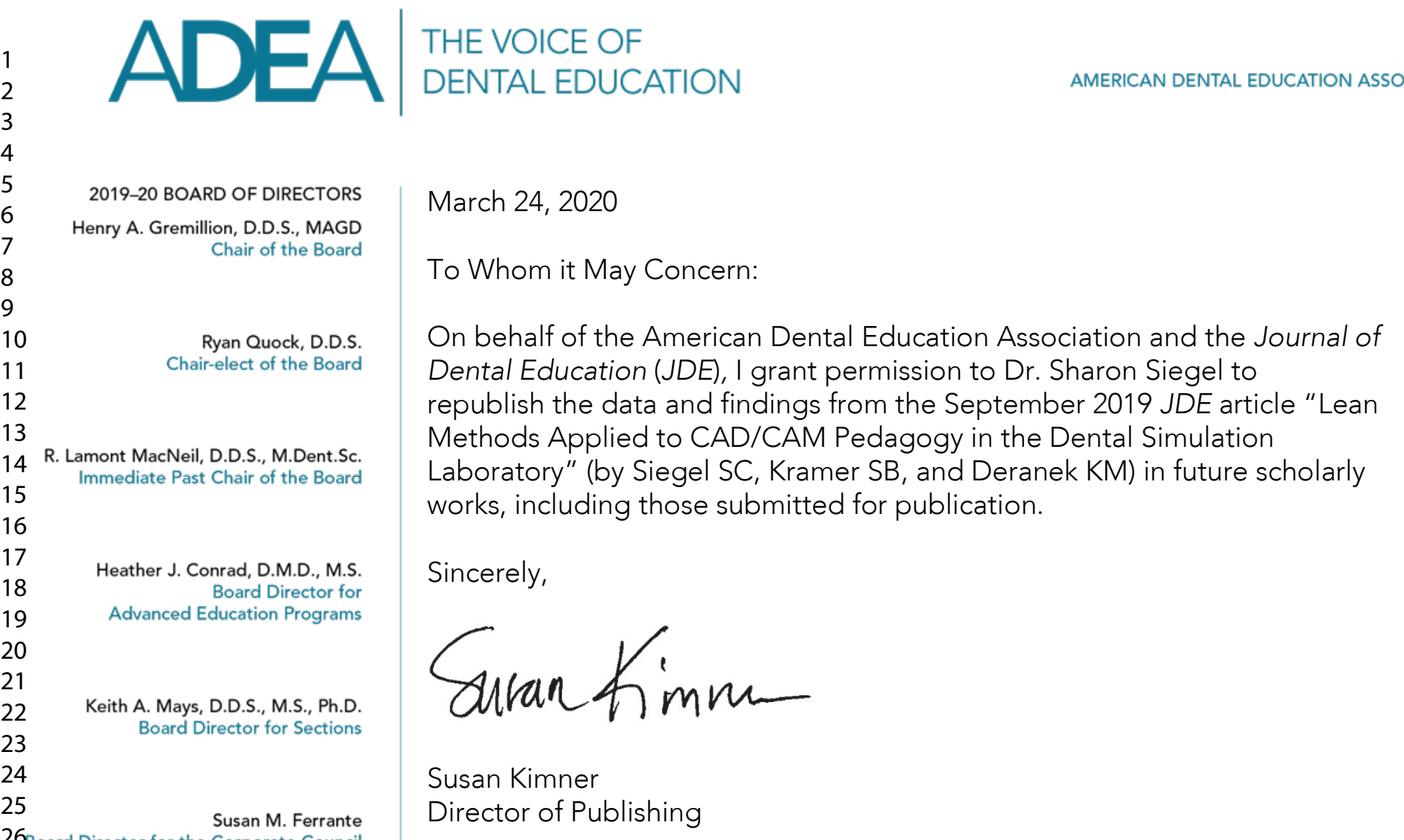

$26_{\text {Board Director for the Corporate Council }}$

Joyce C. Hudson, RDH, M.S. Board Director for Allied Dental Program Directors

Mary Truhlar, D.D.S., M.S. Board Director for Deans

James R. Lott, D.M.D. Board Director for Faculties

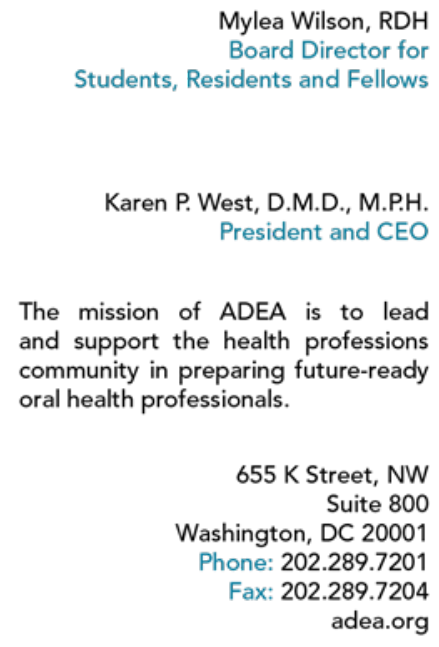


Emerald Group Publishing Limited

Howard House

Wagon Lane

Bingley

West Yorkshire BD16 1WA

\section{Consent to publish - Release form}

Title of Case INSTITUTIONAL REVIEW BOARD OF NOVA SOUTHEASTERN study: UNIVERSITY HEALTH PROFESSIONS DIVISION \#2016-56

Author:

DR. SHARON SIEGEL

I hereby confirm that I have reviewed the above-entitled case study in full and on behalf of the organisation in question, I provide my full permission for the case study to be published in its entirety for the life of the work in all languages and all formats by Emerald Group Publishing for commercial distribution.

By signing this form, I warrant that I am authorised to grant full permission.

\begin{tabular}{|ll|}
\hline Name: & DR. SHARON SIEGEL \\
\hline \hline Position: & $\begin{array}{l}\text { PROFESSOR AND CHAIR IN THE DEPARTMENT OF } \\
\text { PROSTHODONTICS }\end{array}$ \\
\hline \hline Address: & $\mathbf{3 2 0 0}$ S. University Drive, Fort Lauderdale, FL 33228 \\
\hline \hline Organisation: & COLLEGE OF DENTAL MEDICINE \\
\hline \hline E-mail: & scsiegel@nova.edu \\
\hline
\end{tabular}

\section{Signed:}

(either handwritten or insert a scanned image of your signature)

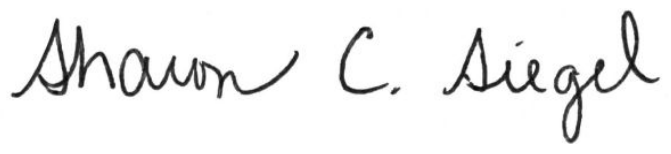

Date reviewed \& signed: 